\title{
Reconstrução cirúrgica após excisão de extenso mixofibrossarcoma do membro superior*
}

\section{Surgical Reconstruction after Resection of a Large Myxofibrossarcoma of the Upper Extremity}

\author{
Kátia Tôrres Batista ${ }^{1}$ Valney Claudino Sampaio Martins ${ }^{1} \quad$ Ulises Prieto y Schwartzman ${ }^{1}$ \\ Telma Leonel Ferreira ${ }^{1}$ \\ ${ }^{1}$ Rede Sarah de Hospitais de Reabilitação, Brasília, DF, Brasil \\ Rev Bras Ortop 2019;54:353-356. \\ Address for correspondence Kátia Tôrres Batista, Rede Sarah de \\ Hospitais de Reabilitação, Brasília, DF, Brasil \\ (e-mail: katiatb@terra.com.br).
}

\author{
Resumo \\ Palavras-chave \\ - sarcoma \\ - neoplasias de tecidos \\ moles \\ - reabilitação
}

O mixofibrossarcoma é um raro sarcoma de partes moles. Os autores apresentam o relato de um caso, em mulher jovem, de exerese e reconstrução de extenso mixofibrossarcoma de baixo grau localizado no antebraço, no punho e na mão. Fez-se a exerese ampla em monobloco conforme achados de ressonância magnética e estudo histopatológico transoperatório. Usaram-se a matriz dérmica e o enxerto de pele total associado a programa fisioterápico pós-operatório. Os aspectos relacionados ao diagnóstico diferencial do mixofibrossarcoma em paciente jovem, seu caráter infiltrativo, a ampla excisão, a reconstrução em dois tempos cirúrgicos (com o uso de matriz dérmica e enxerto de pele total) e o programa fisioterápico pós-operatório são relevantes.

Myxofibrosarcoma is a rare soft tissue sarcoma. The authors present a case report regarding the excision and reconstruction of an extensive low-grade myxofibrosarcoma in the forearm, in the wrist, and in the hand of a young woman. A large-scale monobloc excision was performed according to resonance magnetic imaging (MRI) and transoperative histopathologic study findings. A dermal matrix and total skin graft associated with a postoperative physiotherapy program were used. The aspects related to the differential diagnosis of myxofibrosarcoma in a young patient, its infiltrative character, the extensive excision, the reconstruction in two surgical times (using a dermal matrix and a full-thickness skin graft), and the postoperative physical therapy program were considered important.

\section{Introdução}

O mixofibrossarcoma é um raro tumor originado do tecido conjuntivo. Previamente conhecido como variante mixoide do fibro-histiocitoma maligno. Ocorre principalmente em

Trabalho desenvolvido na Rede Sarah de Hospitais de Reabilitação, Brasília, DF, Brasil. Publicado originalmente por Elsevier Ltda.

received

May 23, 2017

accepted

August 22, 2017
DOI https://doi.org/

10.1016/j.rbo.2017.08.003. ISSN 0102-3616. idosos (60-80 anos), raramente antes dos 20 anos, surge nas extremidades (75\%), tronco (12\%) e mediastino ( $8 \%)^{1,2}$

A metade dos casos se origina na derme e no tecido subcutâneo, o restante na fáscia e no músculo. Histologicamente se caracteriza por crescimento multinodular com estroma mixoide de células fibroblásticas neoplásicas vacuoladas com mucina. As lesões de baixo grau são hipocelulares, compostas de poucas células não coesivas, fusiformes ou
Copyright $(2019$ by Sociedade Brasileira License terms de Ortopedia e Traumatologia. Published by Thieme Revnter Publicações Ltda, Rio de Janeiro, Brazil 
estelares com citoplasma mal definido e núcleos hipercromáticos, com mitoses infrequentes; as de alto grau são compostas de fascículos celulares de fusos e células pleomórficas com mitoses numerosas, atípias e áreas de necrose. No estudo imuno-histoquímico as células tumorais são positivas para vimentina. ${ }^{3}$

Os achados de ressonância magnética (RMN) são inespecíficos, com heterogeneidade, pode evidenciar estroma mixoide. O diagnóstico diferencial deve ser feito com outros tumores de partes moles. 0 tratamento inclui a exérese ampla em monobloco. A recorrência local ocorre em $50-60 \%$ dos casos, independentemente do grau histológico. ${ }^{3-6} 0$ objetivo deste trabalho foi descrever a reconstrução cirúrgica em um caso de extenso mixofibrossarcoma no membro superior.

\section{Relato de caso}

Paciente do sexo feminino, 23 anos, relatava que desde havia dois anos iniciara com dor, edema e aumento de volume na mão, punho e antebraço esquerdos. Submeteu-se a RMN que evidenciou hipótese de hemangioma. Esteve em uso de analgésicos e infiltração com corticoide em outro serviço médico. Ao ser admitida apresentava dor e no exame físico com aumento de volume na mão, no punho e antebraço esquerdos com difícil definição dos limites lesionais.

Submeteu-se a nova RMN que revelou extensa lesão alongada, infiltrativa, com margens indistintas, comprometia o tecido subcutâneo, com aspecto circunferencial no dorso, faces lateral e medial do antebraço distal e mão esquerda ( - Fig. 1). Feitos biópsia e estudo imuno-histoquímico que evidenciaram mixofibrossarcoma (-Fig. 2). A CT de tórax foi normal. Submeteu-se a excisão do tumor no dorso da mão, punho e antebraço que media $20 \times 11 \times 1,5 \mathrm{~cm}$, no plano suprafascial (fáscia, tecido celular subcutâneo e pele), sob anestesia geral e bloqueio do plexo braquial, reconstrução com matriz dérmica (Integra) que media $10 \times 10 \mathrm{~cm}$ sobre os tendões extensores, curativo com carvão ativado, imobilização com tala antebra- quipalmar (-Fig. 3). Instalada analgesia contínua no plexo braquial, controlada pela paciente, com ropivacaína $0,2 \%$ a 5 $\mathrm{mL} /$ hora, bólus de $5 \mathrm{~mL}$ e intervalo de bloqueio de 30 minutos e cefazolina $200 \mathrm{mg}$ dose única. Fez-se troca de curativos semanal sob anestesia. No 21。 dia, fizeram-se ampliação de margem no dorso do III e IV dedos e enxertia de pele total de $20 \times 10 \mathrm{~cm}$ retirada do abdome inferior, curativo atado sobre o enxerto e fechamento primário da área doadora ( - Fig. 4) O curativo foi renovado em uma semana, observou-se integração total do enxerto de pele. Encaminhada para fisioterapia (uso de substância oleosa, malha compressiva, luva flexora, proteção solar, mobilização e alongamento tendíneo, órtese dinâmica com elásticos e turbilhão) (-Fig. 5).

O exame histopatológico revelou pele, tecido celular subcutâneo e fáscia com espessamento difuso, de aspecto tumoral, do terço distal e médio da peça cirúrgica e nodulações gelatinosas que infiltravam toda a espessura e tocavam os limites. Na microscopia evidenciou mixofibrossarcoma de baixo grau (FNCLCC) sem invasão vascular com cariótipo, observou-se um clone normal e um com alterações que envolviam os cromossomos 1,3 e 10; e translocações que envolviam os cromossomos 8 e 1943 45,XX,der(1;3)t(1;3)p31;p21,3)dic(8,19)q24, p13,3)der(10),t(1;10),p31;q25),rob(13;21)(q10;q10)15/46XX (5). O tempo de seguimento foi de um ano sem recidivas.

\section{Discussão}

O mixofibrossarcoma, a depender do grau de celularidade, pleomorfismo nuclear e atividade mitótica, tem sido classificado em três graus histológicos: baixo, intermediário e alto. ${ }^{1,2}$ Neste caso, as características inespecíficas no exame físico e de imagem induziu, em primeira mão, ao diagnóstico de lesão benigna e retardou por mais de dois anos o tratamento. 0 exame de RMN apresentou imagens características, como alto sinal em T2 visto nos tumores mixoides e baixo sinal naqueles com fibrose. Com a RMN não foi possível confirmar o diagnóstico, mas ela foi necessária para o planejamento cirúrgico.

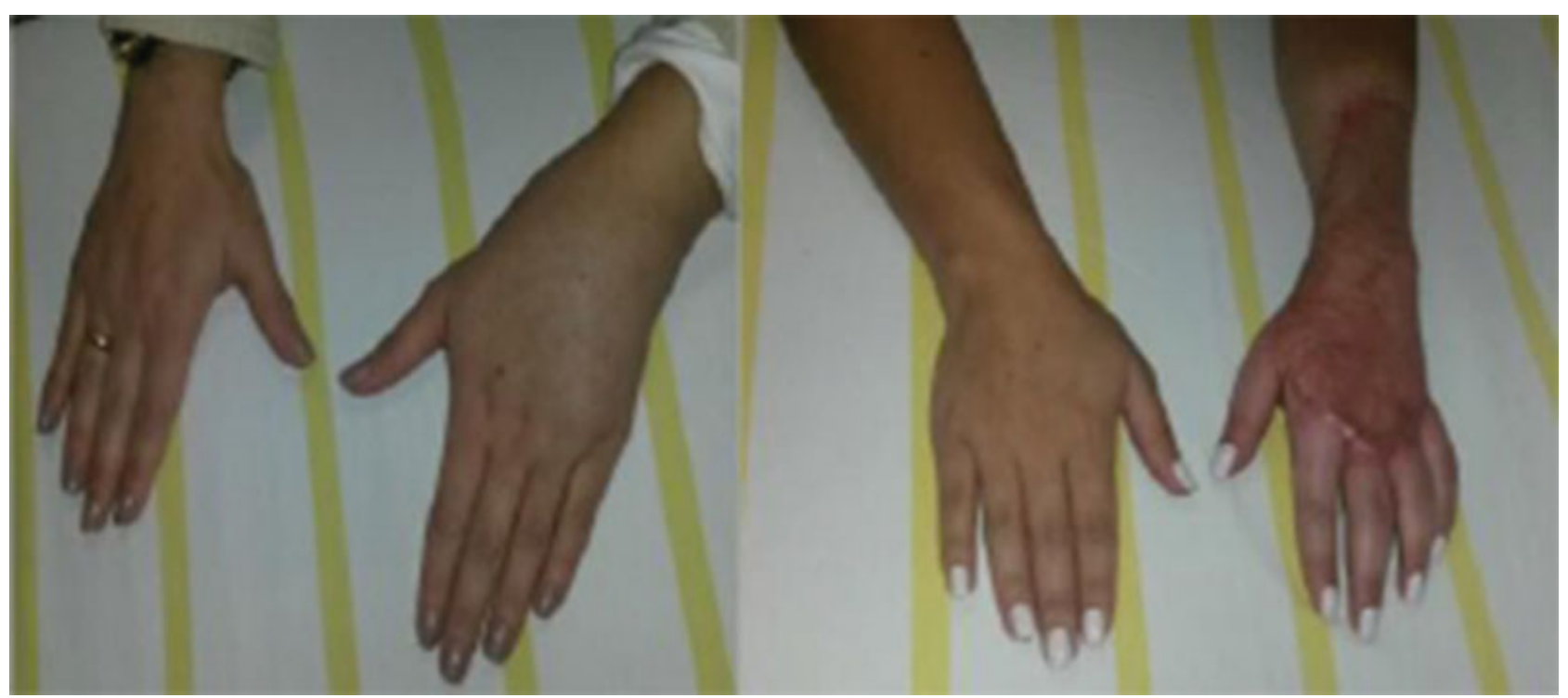

Fig. 1 A, admissão; B, 10 mês pós-operatório. 


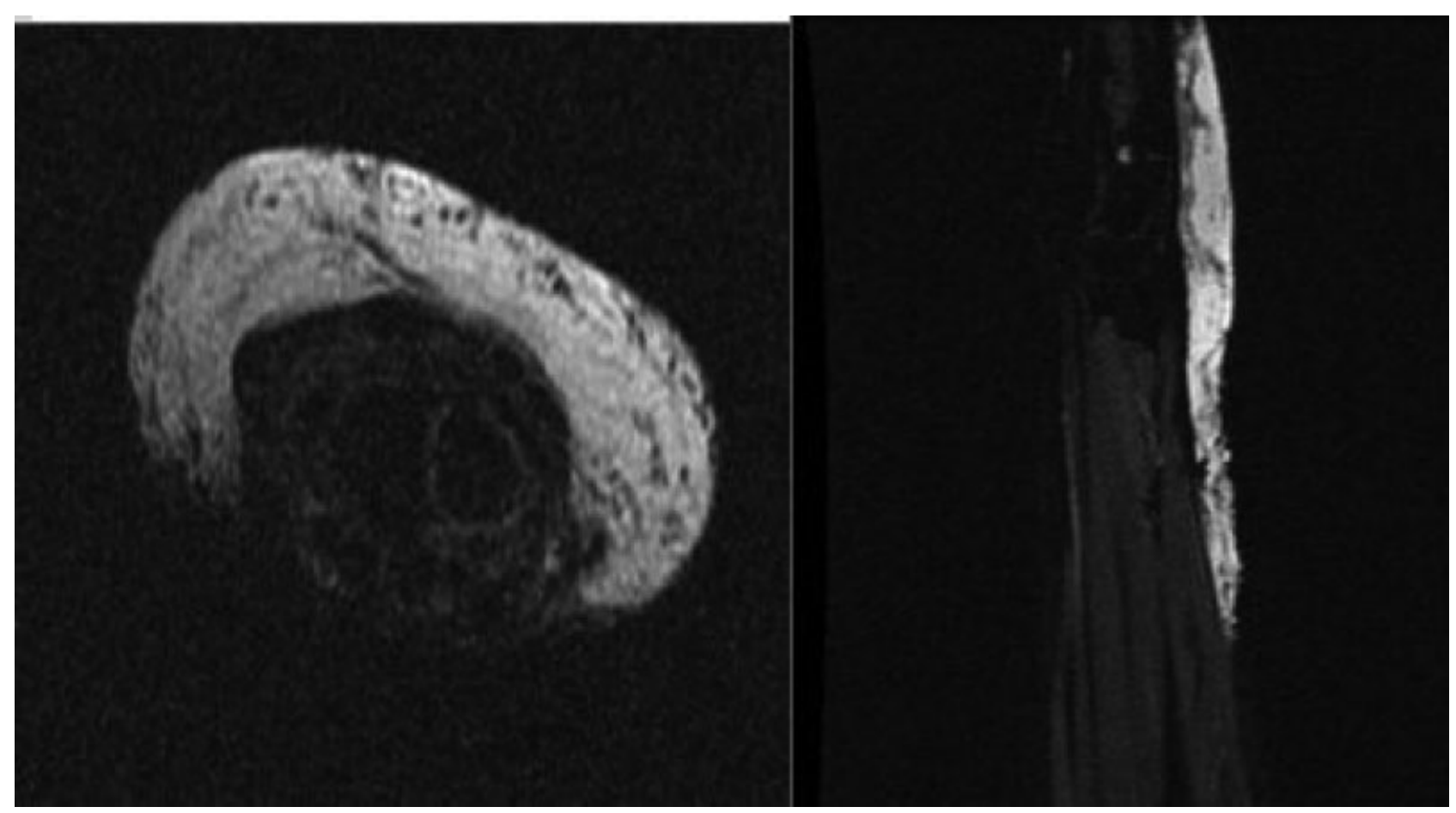

Fig. 2 RMN (Ax GRE T2) lesão infiltrava desde a pele e subcutâneo, profundamente junto ao retináculo dos extensores, com extensão longitudinal de $19 \times 8,5 \times 1,7 \mathrm{~cm}$ (desde o plano do terço médio-distal do rádio até as falanges proximais dos dedos), hipossinal (T1) com áreas entremeadas de alto sinal que indicam tecido gorduroso e alto sinal (T2/STIR) com leve realce com contraste, suspeita de hemangioma.

\begin{tabular}{|l|l|l|l|}
\hline Antígeno & Resultado & Intensidade & Distribuição \\
\hline CD34/Qend/10/Novocastra & Positivo & Forte & Difusa \\
\hline GFAP/6F2/Dako & Negativo & & \\
\hline S100/Policlonal/Dako & Negativo & & \\
\hline Mucin-4(MUC4)/8G7/Santa Cruz & Inconclusivo & & \\
\hline
\end{tabular}

Fig. 3 Resultado de estudo imuno-histoquímico.

A reconstrução após a excisão tumoral foi feita em dois tempos. No primeiro, usou-se material de substituição dérmica por três semanas e no segundo a enxertia de pele total. Para a reconstrução após a excisão de extensos tumores são usados enxertos de pele, retalhos locais e a distância, mais recentemente o uso de matriz dérmica ou sistema de curativo com pressão negativa. ${ }^{7}$ Na década de 1980 , Yannas et $\mathrm{al}^{8,9}$ introduziram o substituto dérmico usado até o presente em uma variedade de feridas. Moiemen et $\mathrm{al}^{10}$ fizeram estudos que avaliaram os estágios de cicatrização na matriz dérmica, da embebição, migração celular, neovascularização, remodelação e maturação. A matriz dérmica foi importante para proteção dos tendões expostos sem o peritendão, estimulação do tecido de granulação favorável para enxertia, quando se obteve o resultado histológico e fez-se a enxertia de pele.

A reconstrução tardia permitiu o resultado histológico definitivo do tumor e das margens cirúrgicas, possibilitou a ampliação das margens duvidosas no dorso do III e IV dedos, que foram negativas no fim. Um dos problemas dos mixofibrossarcomas é a recorrência local, devido ao crescimento difuso, caráter infiltrativo e à difícil definição da margem cirúrgica no transoperatório. O prognóstico depende do grau histológico inicial e do tamanho tumoral. 0 tumor de baixo grau tem comportamento biológico indolente, recorrência local em 50-60\%, sem metástases. As lesões de alto grau têm risco de $30-50 \%$ de metástases, no pulmão, nos ossos e gânglios linfáticos. A profundidade da lesão não influencia a taxa de recorrência local, embora as neoplasias profundas tenham maior percentual de metástases e mortalidade associada, com sobrevida de cinco anos de $60-70 \% .^{2}$ Embora, o tempo de seguimento sem recidiva tenha sido de um ano, há relatos da taxa de recorrência em $25 \%$ dos casos nos cinco primeiros anos após excisão. ${ }^{2,11}$

A apresentação deste caso foi importante como alerta para o diagnóstico diferencial do mixofibrosarcoma de baixo grau com outras patologias no membro superior em paciente jovem e a possibilidade de ampla excisão e reconstrução anatômica e funcional após resultado do exame histopatológico, com matriz dérmica e enxertia de pele total, apesar da extensão e do caráter infiltrativo do tumor. 


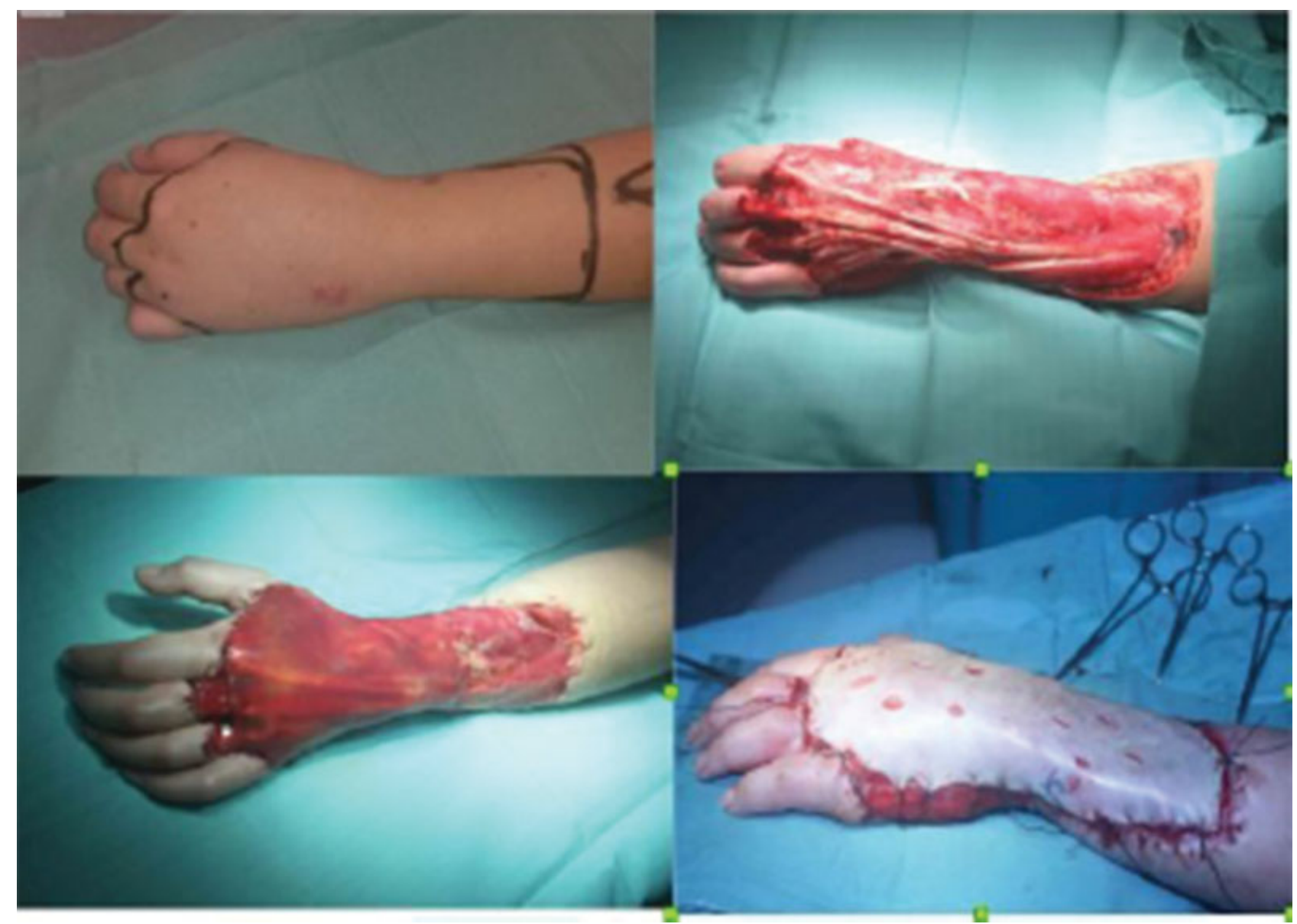

Fig. 4 Transoperatório de exerese de tumor. A, marcação intraoperatória; B, ampla exerese; C, reconstrução com matriz dérmica; D, segundo tempo com a enxertia de pele total.

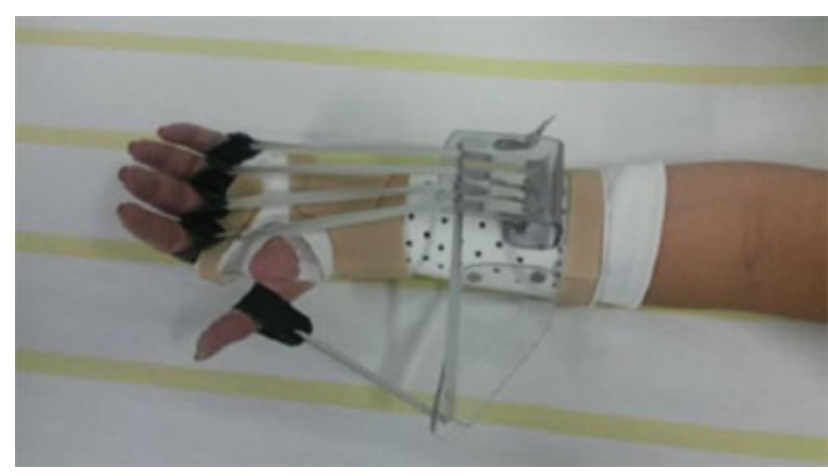

Fig. 5 Uso de órtese dinâmica para exercícios fisioterápicos.

\section{Conflitos de interesse}

Os autores declaram não haver conflitos de interesse.

\section{Referências}

1 Jagannathan JP, Tirumani SH, Ramaiya $\mathrm{NH}$. Imaging in soft tissue sarcomas: current updates. Surg Oncol Clin N Am 2016;25(04): 645-675

2 Dobke M, Mackert GA. Upper extremity sarcoma: impact of current practice guidelines and controversies on reconstructive approaches. SICOT J 2017;3:15
3 Jagtap SV, Jain A, Jagtap SS, Kshirsagar AY. High-grade myxofibrosarcoma-presented as a large mass of right upper arm. Indian J Pathol Microbiol 2015;58(01):105-107

4 Arnaoutoglou C, Lykissas MG, Gelalis ID, Batistatou A, Goussia A, Doukas $M$, et al. Low grade fibromyxoid sarcoma: a case report and review of the literature. J Orthop Surg Res 2010;5:49

5 Fletcher CDM, Bridge JA, Hogendoorn PCW, Mertens F. WHO classification of tumors of soft tissue and bone. 4th ed. Lyon: IARC Press; 2013

6 Clarke LE, Zhang PJ, Crawford GH, Elenitsas R. Myxofibrosarcoma in the skin. J Cutan Pathol 2008;35(10):935-940

7 Bickels J, Kollender Y, Wittig JC, Cohen N, Meller I, Malawer MM. Vacuum-assisted wound closure after resection of musculoskeletal tumors. Clin Orthop Relat Res 2005;441(441):346-350

8 Yannas IV, Burke JF, Orgill DP, Skrabut EM. Wound tissue can utilize a polymeric template to synthesize a functional extension of skin. Science 1982;215(4529):174-176

9 Yannas IV, Lee E, Orgill DP, Skrabut EM, Murphy GF. Synthesis and characterization of a model extracellular matrix that induces partial regeneration of adult mammalian skin. Proc Natl Acad Sci U S A 1989;86(03):933-937

10 Moiemen NS, Staiano JJ, Ojeh NO, Thway Y, Frame JD. Reconstructive surgery with a dermal regeneration template: clinical and histologic study. Plast Reconstr Surg 2001;108(01):93-103

11 Trovik CS, Skjeldal S, Bauer H, Rydholm A, Jebsen N. Reliability of Margin Assessment after Surgery for Extremity Soft Tissue Sarcoma: The SSG Experience. Sarcoma 2012;2012:290698 